\title{
Espécies novas de Paracentronodus Sakakibara, (Homoptera, Membracidae, Centronodinae) ${ }^{1}$
}

\author{
Randal Lopes Barreira ${ }^{2}$ \\ Albino Morimasa Sakakibara ${ }^{3}$
}

\begin{abstract}
New species of Paracentronodus Sakakibara (Homoptera, Membracidae, Centronodinae). Seven new species of Paracentronodus Sakakibara, 1971 from Brazil, are described: P. canarinus sp. n. (type loc.: Pedro Canário, Espírito Santo); P. cristatus sp. n. (type loc.: Sinop, Mato Grosso); P. favisiae sp. n. (type loc.: Encruzilhada, Bahia); $P$. natalinae sp. n. (type loc.: Caraça, Minas Gerais); P. nevesi sp. n. (type loc.: Caruaru, Pernambuco); P. nigrostriatus sp. n. (type loc.: Sinop, Mato Grosso), and $P$. urbanae sp. n. (type loc.: Encruzilhada, Bahia). Hemiptycha viridistriga Walker, 1858, considered by MeTCALF \& WADE (1965) in Hypheodana Metealf, 1952, as Darninae genus, is transferred to Centronodinae, as Paracentronodus viridistriga (Walker, 1858) comb. n. Illustrations and a key for the species are also given. KEY WORDS. Homoptera, Membracidae, Centronodinae, Paracentronodus, new species
\end{abstract}

O gênero Paracentronodus foi descrito por SAKAKIBARA (1971) para abrigar as espécies P. elevatus Sakakibara, 1971 (espécie-tipo) e P. truncatus Sakakibara, 1971, a primeira de Santa Catarina e a segunda de Minas Gerais. Na ocasião, o gênero foi colocado em Centrotinae Amyot \& Serville, 1843, subfamília cuja característica principal é o escutelo exposto. DeITz (1975) considerou os membracídeos com o escutelo exposto em duas subfamílias: Centrotinae e Stegaspinae [sic] Haupt, 1929, tomando por base a configuração do clavo nas tégminas. Criou, dentro de Stegaspidinae, a tribo Centronodini onde incluiu Centronodus Funkhouser, 1930 e Postanomus Funkhouser, 1950. DeITz \& DieTrICH (1993) elevaram Centronodini Deitz, 1975 para a categoria de subfamília, Centronodinae, e transferiram para ela o gênero Paracentronoduss Sakakibara, 1971. Durante os estudos dos Centronodinae, verificou-se através de um diapositivo que Hemiptycha viridistriga Walker, 1858, considerada por METCALF \& WADE (1965) como Hypheodana Metcalf, 1952, um gênero de Darninae Amyot \& Serville, pertence a Paracentronodus.

O material utilizado no presente estudo pertence à Coleção de Entomologia Pe. J.S. Moure, Departamento de Zoologia, Universidade Federal do Paraná, (DZUP).

1) Contribuição número 1248 do Departamento de Zoologia, Universidade Federal do Paraná.

2) Curso de Pós-Graduação em Entomologia, Universidade Federal do Paraná. Bolsista da CAPES.

3) Departamento de Zoologia, Universidade Federal do Paraná. Caixa Postal 19020, 81531-990 Curitiba, Paraná, Brasil. Bolsista do CNPq. 


\section{Chave para as espécies}

1. Elevação dorsal bem pronunciada, em vista lateral, com as margens anterior e posterior subparalelas . . . . . . . . . . . . . . . . . . . 2

- Elevação dorsal pouco pronunciada, em vista lateral, em forma de crista com a

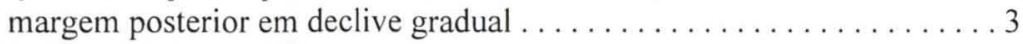

2. Elevação dorsal obliquamente truncada no ápice, de altura (a partir do escutelo) superior à largura da tégmina .................. cristatus $\mathbf{s p .} \mathbf{n}$.

- Elevação dorsal horizontalmente truncada no ápice, de altura inferior à largura da tégmina ........................ truncatus Sakakibara

3. Processo posterior não atingindo o ápice do clavo $\ldots \ldots \ldots \ldots \ldots \ldots \ldots$

- Processo posterior atingindo ou ultrapassando o ápice do clavo .........5

4. Dorso do pronoto quase na mesma altura do metopídio ....... P. nevesi $\mathbf{s p .} \mathbf{n}$.

- Dorso do pronoto elevado em forma de crista mais ou menos arredondada ..... P. viridistriga (Walker) comb. $\mathbf{n}$.

5. Elevação dorsal com a margem anterior abrupta $\ldots \ldots \ldots \ldots \ldots \ldots \ldots 6$

- Elevação dorsal com a margem anterior suavemente inclinada . . . . . . . . 7

6. Processo posterior com a área amarelada pré-apical bem definida . . . . . . . . . . P. favisiae sp. $\mathbf{n}$.

- Processo posterior com a área amarelada pré-apical indistinta..

P. elevatus Sakakibara

7. Pronoto com uma estria negra ao longo da carena média, bifurcada logo antes da área clara pré-apical . .................. . nigrostriatus $\mathbf{s p .} \mathbf{n}$.

- Pronoto sem tal estria ou, quando muito, apenas na parte mais elevada ou em forma de mancha a cada lado $\ldots \ldots \ldots \ldots \ldots \ldots \ldots \ldots \ldots \ldots \ldots$

8. Pronoto em vista lateral, com contorno superior em arco regular ........... P. urbanae sp. $\mathbf{n}$.

- Pronoto em vista lateral, distintamente elevado depois dos ângulos umerais ...9 9. Parte mais elevada do pronoto situada acima do escutelo ....P. natalinae $\mathbf{s p .} \mathbf{n}$. - Parte mais elevada do pronoto situada depois do escutelo ...P. canarinus $\mathbf{s p .} \mathbf{n}$.

\section{Paracentronodus canarinus sp. $\mathbf{n}$.}

Figs $1-5,26$

Diagnose. Pronoto pouco elevado, apenas angulado acima do escutelo; processos supra-umerais curtos; processo posterior terminando na altura do ápice do clavo.

Medidas (mm). Macho: comprimento total 6,67; comprimento do pronoto 5,83; comprimento da cabeça 1,25; largura da cabeça 2,92; largura entre os ângulos umerais 2,83; distância entre os ápices dos processos supra-umerais 3,50; comprimento das tégminas 5,83; comprimento das asas 5,25. 

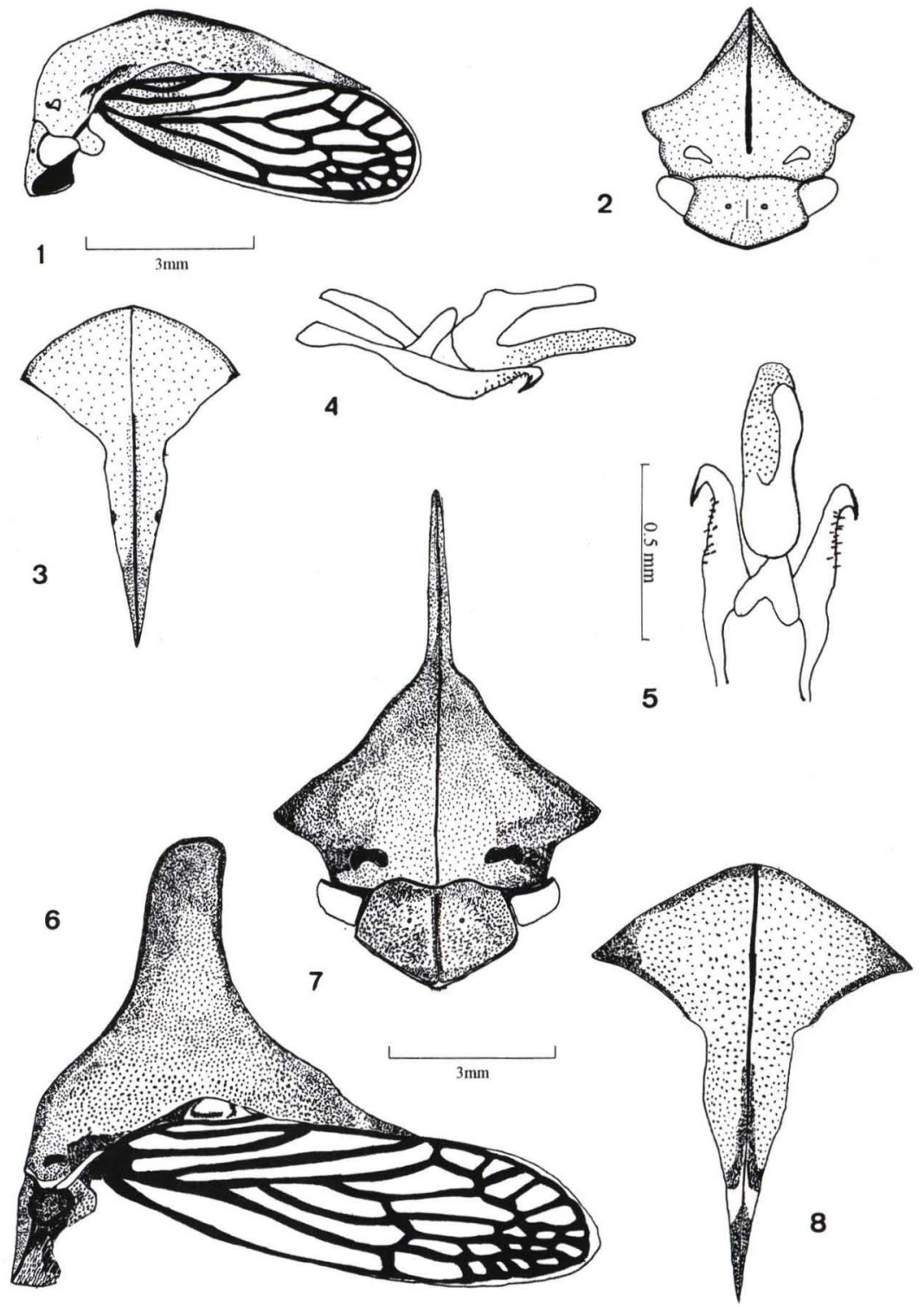

Figs 1-8. (1-5) Paracentronodus canarinus sp. n.: (1) vista lateral; (2) frontal; (3) dorsal; (4-5) genitália; (6-8) P. cristatus sp. n.: (6) vista lateral; (7) frontal; (8) dorsal.

Descrição. Holótipo macho. Cabeça subtriangular, cinza-esverdeada, densamente pontuada com castanho-escuro; ápice do clípeo não sobressaindo às margens inferiores dos lóbulos supra-antenais; sutura epistomal arqueada; superfície dos lóbulos supra-antenais plana, textura lisa, margens inferiores arredondadas; espaços interocelar e ocelo-oculares planos; ocelos situados abaixo da linha imaginária que 
passa pelo centro dos olhos, mais próximos entre si; olhos alongados, fuscos; sutura coronal atingindo a base do clípeo; margem superior do vértice sinuosa. Pronoto cinza-esverdeado, densamente pontuado, com pontuações castanho-escuras, com duas manchas pretas nas laterais, uma faixa castanho-escura na parte pré-apical alargando-se até encobrir todo o final do pronoto; superfície dos lóbulos pós-oculares rugosas; metopídio arredondado; distância entre os ângulos umerais menor que a largura entre os ápices dos processos supra-umerais; processos supra-umerais curtos, menores que o comprimento da cabeça, de forma cônico-achatada, dirigidos para os lados, sem inclinação, sem carena, com superfície rugosa, com o ápice castanho-escuro; margem anterior da elevação dorsal arredondada, declive posterior leve; ápice do pronoto gradativamente agudo, terminando na altura do ápice do clavo. Escutelo visível lateralmente. Tégminas com a parte basal coriácea, com o mesmo padrão de coloração do pronoto; parte distal hialina com venação castanhoclara. Asas hialinas com venação escura. Genitália: edeago cilíndrico, alongado, ápice liso, parte mediana com muitos dentículos; falobase cilíndrica; parâmeros robustos e curtos, terminados em gancho; conectivo largo e mais ou menos triangular.

Material examinado. Holótipo macho de "Pedro Canário -Espírito Santo Brasil - Conceição da Barra, X - 1972, M. Alvarenga - leg." Parátipo: 1 macho com os mesmos dados do holótipo. (DZUP).

Etimologia. O nome da espécie é alusivo ao nome da localidade-tipo.

Comentários. Apresenta uma leve semelhança com P. nigrostriatus sp. $\mathbf{n}$. quanto à forma do pronoto. Aproxima-se também de $P$. viridistriga (Walker) pela presença da área clara pré-apical bem definida. Em $P$. viridistriga a elevação dorsal é mais pronunciada e o ápice do processo posterior não chega ao final do clavo.

\section{Paracentronodus cristatus sp. $\mathbf{n}$.}

Figs 6-8, 27

Diagnose. Pronoto com a elevação dorsal bem pronunciada, de altura superior ao comprimento do processo posterior, com os lados subparalelos e o ápice obliquamente truncado; processo posterior terminando na altura do ápice do clavo.

Medidas (mm). Fêmea: comprimento total 9,52; comprimento do pronoto 9,00; largura da cabeça 3,92; comprimento da cabeça 1,83; largura entre os ângulos umerais 3,92 ; distância entre os ápices dos processos supra-umerais 5,33; comprimento das tégminas 8,33 .

Descrição. Holótipo fêmea. Cabeça duas vezes mais larga que longa, subtriangular, acastanhada, com manchas castanho-escuras, fortemente pontuada; clípeo mais longo que largo, piriforme, com a margem inferior no mesmo nível das margens inferiores dos lóbulos supra-antenais; sutura epistomal arqueada; superfície dos lóbulos supra-antenais plana, textura rugosa, margens foliáceas; espaços interocelar e ocelo-oculares planos; sutura coronal atingindo a base do clípeo, mais profunda entre os ocelos; ocelos de coloração amarelada, eqüidistantes entre si e dos olhos, situados abaixo da linha imaginária que passa pelo centro dos olhos; olhos ovóides, alongados; margem superior do vértice sinuosa. Pronoto com o mesmo 
padrão de coloração da cabeça; pontuação homogênea; superfície dos lóbulos pós-oculares rugosa; metopídio arredondado; distância entre os ângulos umerais menor que a largura entre os ápices dos processos supra-umerais; processos supraumerais menores que o comprimento da cabeça, de forma cônico-achatada, dirigidos para os lados; elevação dorsal bem pronunciada, de altura superior a duas vezes o comprimento da cabeça, com os lados subparalelos, obliquamente truncado no ápice, com uma estreita faixa contornando a carena dorsal; área pré-apical com uma estreita faixa amarela; ápice do processo posterior de cor castanho-escura, terminando na altura do ápice do clavo. Escutelo visível lateralmente. Tégminas com o mesmo padrão de coloração do pronoto, parte apical enfumaçada e com venação castanho-clara. Asas hialinas, com venação castanho-escura. Pernas castanho-claras, manchadas com castanho-escuro. Tórax e abdômen de cor bege com máculas castanho-escuras.

Material examinado. Holótipo fêmea de "Sinop-MT [Mato Grosso], Brasil, X/1975, M. Alvarenga leg." (DZUP).

Etimologia. O nome da espécie é alusivo à elevação dorsal do pronoto bem desenvolvida, em forma de uma crista.

Comentários. Esta espécie é a maior de todas. A forma do pronoto é também peculiar, apresentando a elevação dorsal projetada verticalmente entre os processos supra-umerais e o escutelo, com altura superior à largura da cabeça. Aproxima-se de $P$. truncatus quanto à forma do pronoto porém, em $P$. truncatus, a elevação dorsal localiza-se logo depois do escutelo.

\section{Paracentronodus favisiae sp. $\mathbf{n}$.}

Figs 4, 17-19

Diagnose. Elevação dorsal do pronoto com a margem anterior abrupta e a posterior em declive gradual; área clara pré-apical bem evidente; com uma mancha escura arredondada de cada lado, logo atrás do escutelo, junto às margens. Ápice do processo posterior ultrapassando o ápice do clavo.

Medidas $(\mathrm{mm})$. Fêmea: comprimento total 7,75; comprimento do pronoto 6,92; largura da cabeça 3,08; comprimento da cabeça 1,33; largura entre os ângulos umerais 3,33 ; distância entre os ápices dos processos supra-umerais 4,58; comprimento das tégminas 6,42; comprimento das asas 6,08.

Descrição. Holótipo fêmea. Cabeça castanho-clara, de forma subtriangular, quase duas vezes e meia mais larga que o seu comprimento, densamente pontuada com castanho-escuro; clípeo mais longo que largo, piriforme, um pouco mais escuro que o restante da cabeça, com a margem inferior no mesmo nível dos lóbulos supra-antenais; sutura epistomal arqueada; superfície dos lóbulos supra-antenais plana, com textura rugosa, margens arredondadas; espaços interocelar e ocelo-oculares planos; olhos ovalados; ocelos amarelo-mélicos, localizados sobre a linha imaginária que passa pelo centro dos olhos, eqüidistante entre si e dos olhos; sutura coronal não atingindo a base do clípeo; margem superior do vértice reta. Pronoto com a mesma coloração e pontuação da cabeça, com uma mancha preta, arredondada, de cada lado logo atrás do escutelo, junto às margens laterais; elevação dorsal 


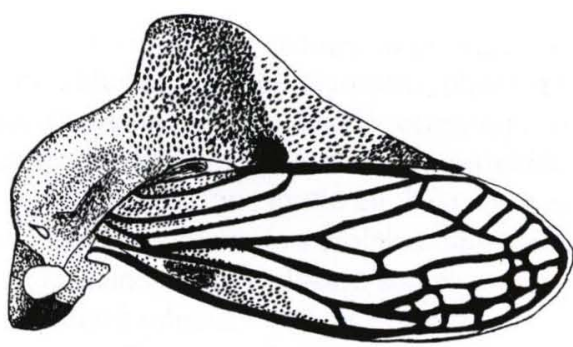

9
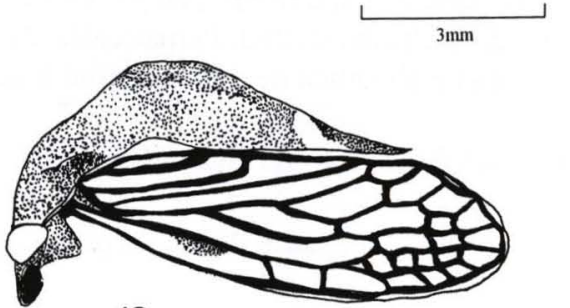

12

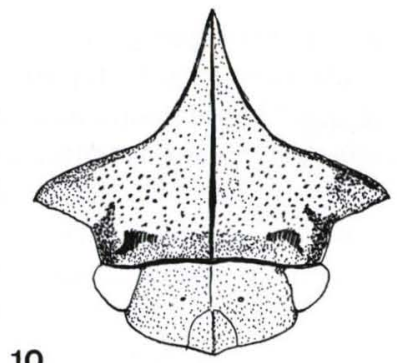

10

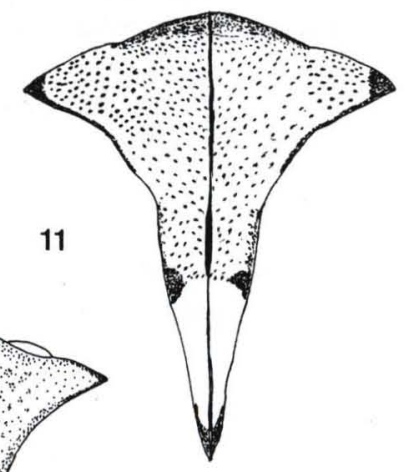

14

13
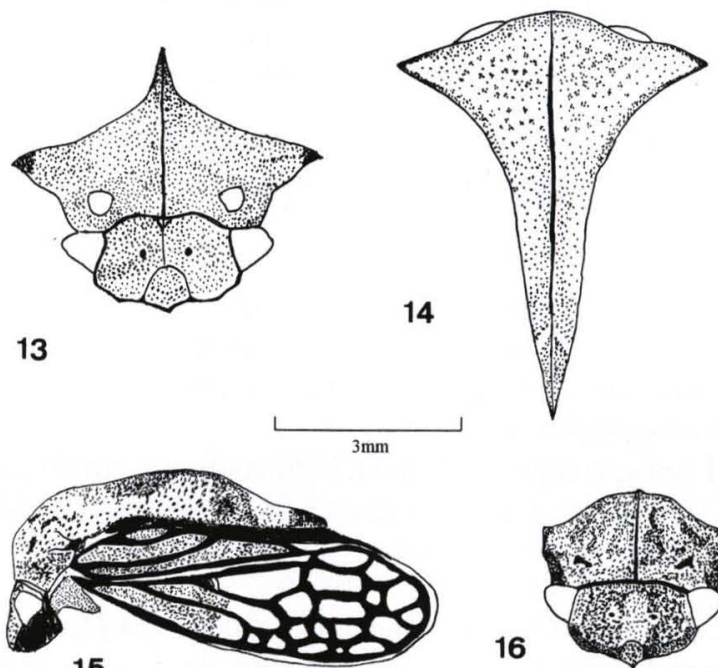

15
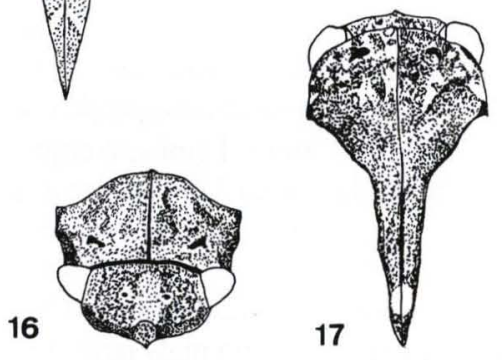

Figs 9-17. (9-12) Paracentronodus favisiae sp. n.: (9) vista lateral; (10) frontal; (11) dorsal; (12-14) P. natalinae sp. n.: (12) vista lateral; (13) frontal; (14) dorsal; (15-17) P. nevesi sp. $\mathbf{n}$.: (15) vista lateral; (16) frontal; (17) dorsal.

obliquamente truncada, mais baixa que a largura da cabeça; área pré-apical amarela, bem distinta; ápice do processo posterior castanho-escuro, atingindo o ângulo interno das tégminas; superfície dos lóbulos pós-oculares rugosa; metopídio arredondado; distância entre os ângulos umerais menor que a largura entre os ápices 
dos processos supra-umerais; processos supra-umerais com o comprimento menor que o comprimento da cabeça, de forma cônico-achatada, de cor castanho-escura, mais acentuada em seus ápices; elevação dorsal obliquamente truncada, mais larga que alta, com a margem anterior abrupta e a posterior em declive gradual; ápice do processo posterior atingindo o ângulo interno das tégminas; escutelo visível lateralmente. Tégminas com a mesma cor do pronoto, com uma mancha negra na margem costal, parte distal hialina, com venação bem desenvolvida de cor castanho-escura. Asas hialinas, com venação castanho-escura. Pernas castanho-claras; tíbias com manchas escuras transversais. Tórax e abdômen castanho-claros.

Material examinado. Holótipo fềmea de "Encruzilhada - Bahia -Brasil-980 m., XI/1974. M. Alvarenga leg.". Parátipos: 2 fêmeas de "Corcovado - Rio de Janeiro - Brasil X 1968, Fragoso leg." (DZUP).

Etimologia. O nome da espécie é em homenagem à colega Favisía Freitas de Oliveira.

Comentários. Esta espécie é muito próxima de $P$. elevatus, no seu aspecto geral; difere pelos processos supra-umerais inclinados para baixo, presença de uma mancha negra na região basal das asas; a elevação dorsal com declive posterior gradual.

\section{Paracentronodus natalinae sp. $\mathbf{n}$.}

Figs $5,20-22$

Diagnose. Pronoto com a elevação dorsal pouco desenvolvida, com a margem anterior inclinada e a posterior em declive gradual até o ápice do processo posterior, este atingindo o ângulo interno das tégminas; área clara pré-apical estreita e oblíqua.

Medidas (mm). Macho: comprimento total 7,42; comprimento do pronoto 6,17; largura máxima da cabeça 3,08; comprimento da cabeça 1,25; largura entre os ângulos umerais 3,17 ; distância entre os ápices dos processos supra-umerais 4,50 ; comprimento das tégminas 6,50; comprimento das asas 5,67.

Descrição. Holótipo macho. Cabeça sub-retangular, duas vezes mais larga que longa; clípeo tão largo quanto longo, piriforme, margem inferior no mesmo nível das margens dos lóbulos supra-antenais; sutura epistomal arqueada; superfície dos lóbulos supra-antenais plana, com textura rugosa, margens foliáceas, arredondadas; espaços interocelar e ocelo-oculares planos; ocelos castanho-escuros, localizados abaixo da linha imaginária que passa pelo centro dos olhos, eqüidistantes entre si e dos olhos; olhos ovalados, pretos; sutura coronal atingindo a base do clípeo; margem superior do vértice sinuosa. Pronoto de coloração castanho-clara, manchado com castanho-escuro, densamente pontuado com preto; superfície dos lóbulos pós-oculares pontuada; metopídio arredondado; distância entre os ângulos umerais menor que a largura entre os ápices dos processos supra-umerais; processos supraumerais de forma cônico-achatada, ápices sem carena, superfície rugosa; elevação dorsal pouco pronunciada, mais ou menos arredondada, com a parte anterior inclinada e a posterior em declive gradual; área pré-apical amarelada. Escutelo visível lateralmente. Tégminas com a região basal coriácea e a parte distal transparente; venação castanha. Asas hialinas, com venação preta. Pernas castanho-escuras. Tórax negro. Abdômen negro com as partes laterais bege avermelhadas. 


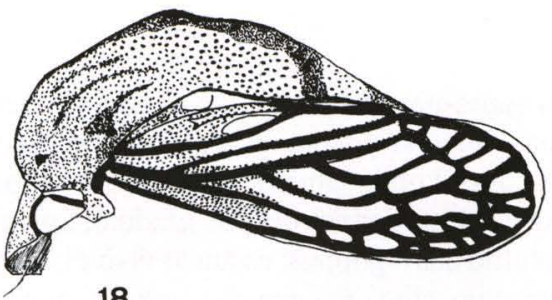

18

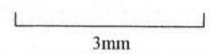

19

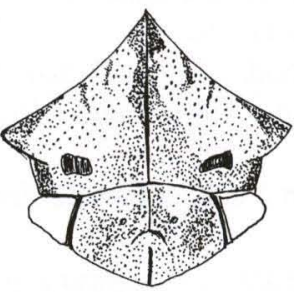

20

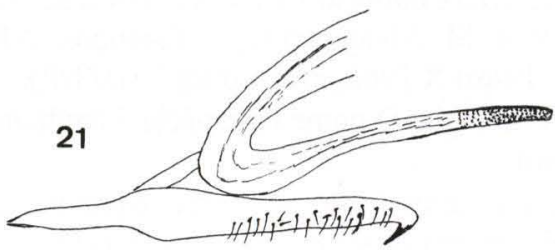

$0,5 \mathrm{~mm}$
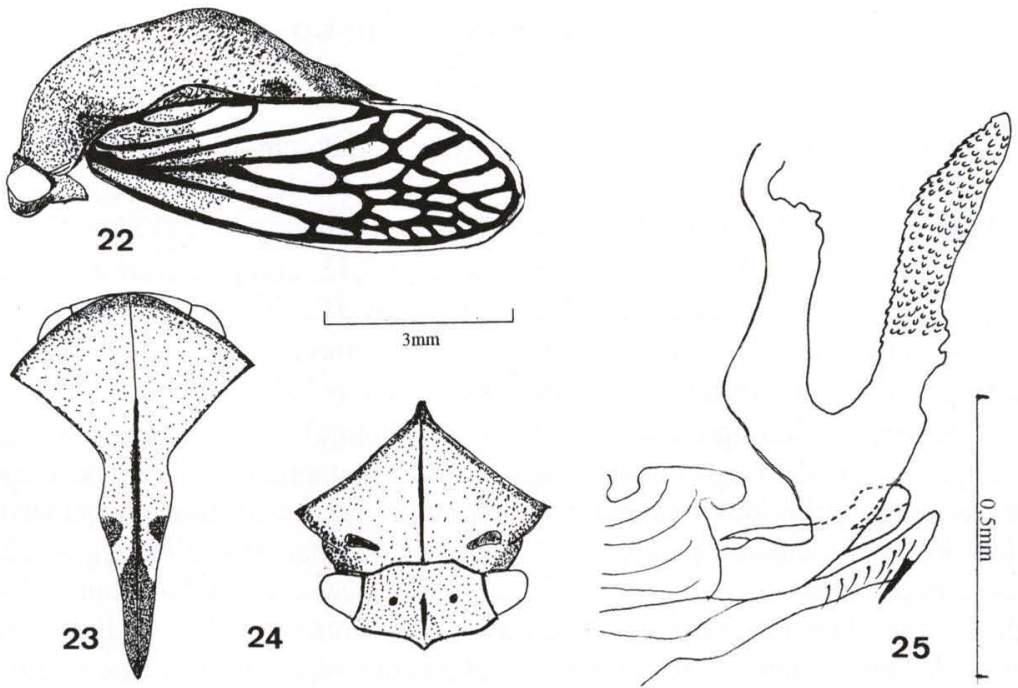

Figs 18-25. (18-21) Paracentronodus nigrostriatus sp. n.: (18) vista lateral; (19) dorsal; (20) frontal; (21) genitália; (22-25) P. urbanae sp. n.: (22) vista lateral; (23) dorsal; (24) frontal; (25) genitália.

Material examinado. Holótipo macho de "Caraça -Santa Barbara- MG [Minas Gerais]- Brasil I-1971, F.M. Oliveira leg." (DZUP).

Etimologia. A espécie é em homenagem a Natalina P.S. Lopes.

Comentários. Esta espécie fica entre $P$. favisiae sp. n. e $P$. canarinus sp. n. ao se observar a forma da elevação dorsal do pronoto. Difere de ambas por não apresentar a mancha negra lateral nem a área clara pré-apical larga e distinta. 


\section{Paracentronodus nevesi sp. $\mathbf{n}$.}

Figs 6, 23-25

Diagnose. Pronoto baixo, praticamente sem elevação dorsal; processos supra-umerais curtos; processo posterior terminando antes do ápice do clavo.

Medidas (mm). Macho. Comprimento total 7,04; comprimento do pronoto 5,17; largura da cabeça 2,67; comprimento da cabeça 1,00; largura entre os ângulos umerais 2,50; distância entre os ápices dos processos supra-umerais 2,75; comprimento das tégminas 5,17; comprimento das asas 4,08.

Descrição. Holótipo macho. Cabeça transversa, duas vezes e meia mais larga que longa, de forma sub-retangular; clípeo tão largo quanto longo, piriforme, com o ápice no mesmo nível das margens dos lóbulos supra-antenais; sutura epistomal arqueada; superfície dos lóbulos supra-antenais plana, textura rugosa; espaços interocelar e ocelo-oculares planos; ocelos de coloração negra, localizados abaixo da linha imaginária que passa pelo centro dos olhos, mais próximos entre si; olhos ovalados, de coloração fusca; sutura coronal não atingindo a base do clípeo; vértice amplo, um pouco abaulado, com as bordas superiores sinuosas. Pronoto de coloração castanhoescura, com manchas claras, pontuação homogênea; uma pequena mancha amarela na parte pré-apical; parte apical castanho-escura, terminando antes do ápice do clavo; carena dorsal saliente; superfície dos lóbulos pós-oculares rugosa; metopídio arredondado; distância entre os ângulos umerais menor que a largura entre os ápices dos processos supra-umerais; processos supra-umerais reduzidos, de comprimento menor que o comprimento da cabeça, cônico-achatados, dirigidos para os lados e para trás; elevação dorsal obsoleta, em forma de meia-lua, margem anterior arredondada, declive posterior gradual. Escutelo visível lateralmente. Tégminas com a parte basal coriácea, com o mesmo padrão de coloração do pronoto; parte distal hialina. Pernas castanhoescuras. Tórax e abdômen de cor bege, com máculas pretas.

Material examinado. Holótipo macho de "Caruaru - Pernambuco -Brasil, II - 1972, M. Alvarenga leg.". (DZUP)

Etimologia. O nome da espécie é em homenagem ao amigo Adenomar Neves de Carvalho.

Comentários. Esta espécie é a menor do gênero. O pronoto é curto e baixo, não destacando a elevação dorsal como nas outras espécies. Os processos supraumerais também são muito curtos, mais ou menos cônicos. Aproxima-se, de certa forma, à $P$. urbanae sp. $\mathbf{n}$.

\section{Paracentronodus nigrostriatus sp. $\mathbf{n}$.}

Figs $18-21,31$

Diagnose. Pronoto pouco elevado dorsalmente, apenas angulado acima do escutelo, ornado com uma estria negra sobre a carena dorsal, bifurcada antes da área clara pré-apical.

Medidas (mm). Macho/fêmea: comprimento total 8,08/9,33; comprimento do pronoto $6,25 / 6,92$; largura da cabeça $3,50 / 3,75$; comprimento da cabeça 1,50 / 1,67; largura entre os ângulos umerais $3,33 / 3,75$; comprimento das tégminas $6,42 / 7,50$; comprimento das asas $5,42 / 6,50$. 
Descrição. Holótipo macho. Cabeça castanho-clara, com máculas castanhoescuras, de forma subtriangular, transversal, duas vezes mais larga que longa; clípeo castanho-claro, pontilhado com castanho-escuro, mais longo que largo, piriforme, com a margem inferior no mesmo nível das margens dos lóbulos supra-antenais; sutura epistomal arqueada; superfície dos lóbulos supra-antenais côncava, com textura rugosa, margens foliáceas; espaço interocelar plano; espaços ocelo-oculares côncavos; ocelos amarelo-mélicos, situados acima da linha imaginária que passa pelo centro dos olhos, eqüidistantes entre si e dos olhos; olhos ovalados, de cor amarelo-acastanhada; sutura coronal atingindo a base do clípeo; vértice amplo, com margem superior arqueada. Pronoto com pontuação heterogênea, castanho-claro com rajás castanho-escuros, uma faixa preta ao longo da carena média dorsal, bifurcada pouco antes da área clara pré-apical; superfície dos lóbulos pós-oculares rugosa; metopídio arredondado; distância entre os ângulos umerais menor que a largura entre os ápices dos processos supra-umerais; processos supra-umerais de forma cônico-achatada, dirigidos para os lados; elevação dorsal pouco pronunciada, apenas angulada acima do escutelo, com a margem anterior arredondada, declive posterior gradual; ápice do pronoto gradativamente agudo, atingindo o ápice do clavo. Escutelo visível lateralmente. Tégminas com a parte basal coriácea, densamente pontuada com castanho-claro. Pernas simples, castanho-claras com manchas castanho-escuras. Genitália: edeago, visto lateralmente, achatado, delgado, alongado, com o ápice mais estreito e coberto com microesculturações em forma de escamas; parâmeros com a base larga, próximo do conectivo estreitando-se para o ápice e terminados em gancho de ponta longa.

Fêmea. Com as mesmas características do macho, porém um pouco maior.

Material examinado. Holótipo macho de "Sinop - Mato Grosso -Brasil X 1975, M. Alvarenga leg.". Parátipos: 4 machos e 1 fêmea, com mesmos dados do holótipo; 1 macho da mesma localidade, com data de X-1974.

Etimologia. $\mathrm{O}$ nome da espécie é alusivo à presença da faixa negra sobre $\mathrm{a}$ carena dorsal.

Comentários. Está espécie é mais ou menos parecida com $P$. canarinus $\mathbf{s p}$. n. pela forma geral do pronoto, com a elevação dorsal pouco pronunciada. Distingue-se entretanto, pela presença da estria negra sobre a carena dorsal.

\section{Paracentronodus urbanae sp. $\mathbf{n}$.}

Figs 22-25, 32

Diagnose. Pronoto com o contorno dorsal regularmente arqueado, com a parte elevada situada acima do escutelo. Coloração geral uniforme, com uma mancha negra de cada lado logo atrás do escutelo; área clara pré-apical indefinida.

Medidas (mm). Macho. Comprimento total 7,83; comprimento do pronoto 5,42; largura da cabeça 3,33; comprimento da cabeça 1,08; largura entre os ângulos umerais 3,25 ; distância entre os ápices dos processos supra-umerais 3,33; comprimento das tégminas 6,17; comprimento das asas 5,42.

Descrição. Holótipo macho. Cabeça transversa, de forma sub-retangular, castanho-clara, densamente pontuada com preto, quase quatro vezes mais larga que

Revta bras. Zool. 18 (Supl. 1): 255 - 267, 2001 

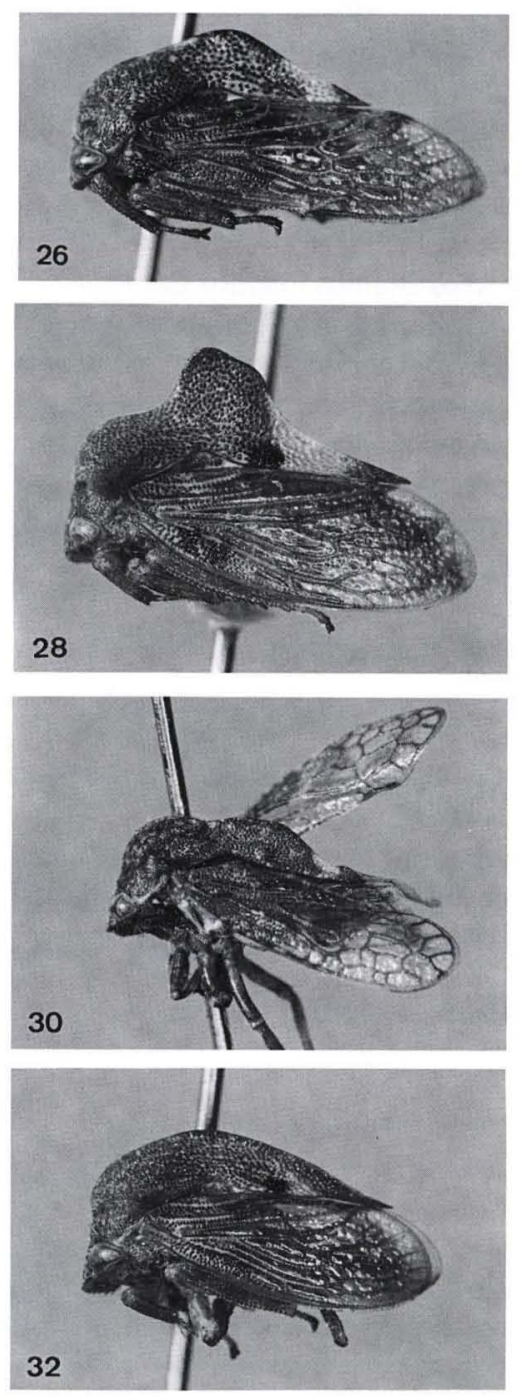
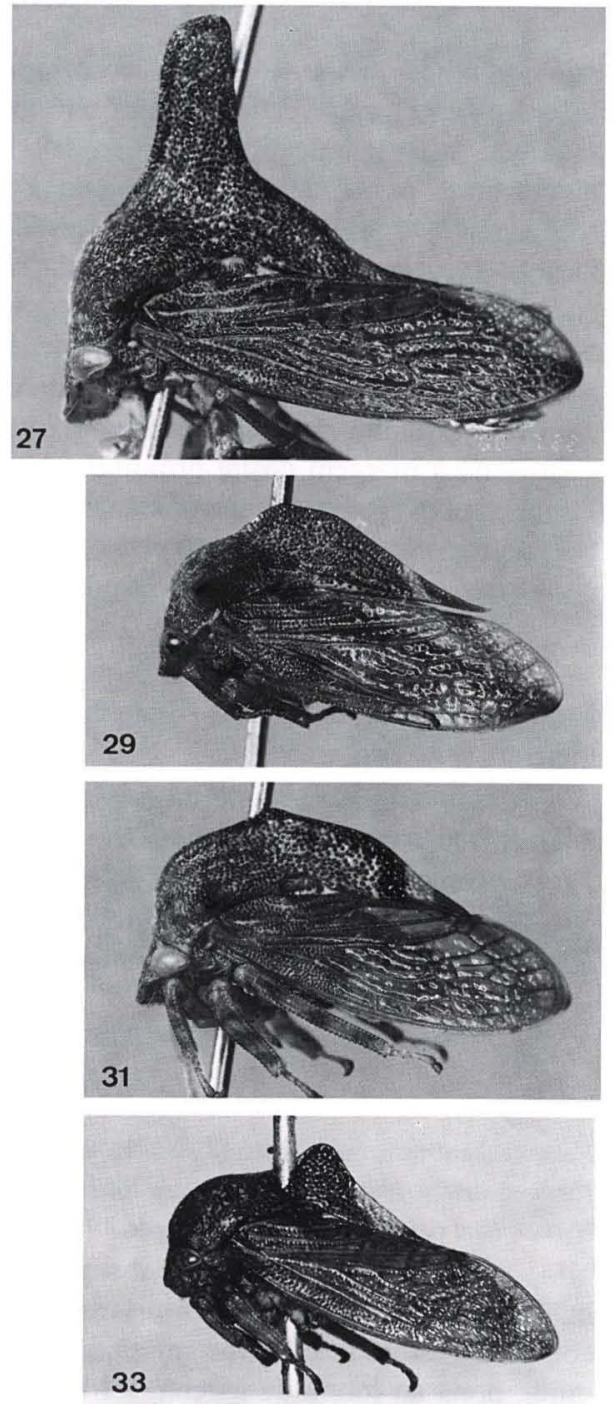

Figs 26-33. (26) Paracentronodus canarinus sp. n., holótipo macho; (27) P. cristatus sp. n., holótipo fêmea; (28) $P$. favisiae sp. n., holótipo fêmea; (29) $P$. natalinae sp. n., holótipo macho; (30) P. nevesi sp. n., holótipo macho; (31) P. nigrostriatus sp. n., holótipo macho; (32) $P$. urbanae sp. n., holótipo macho; (33) $P$. viridistriga, lectótipo fêmea.

longa; clípeo mais largo que longo, de forma subtriangular, margem inferior no mesmo nível da margem dos lóbulos supra-antenais; sutura epistomal arqueada; superfícies dos lóbulos supra-antenais plana, textura lisa, margens foliáceas dobradas para trás; espaço interocelar côncavo e os ocelo-oculares planos; ocelos situados sobre a linha imaginária que passa pelo centro dos olhos, mais próximos entre si do 
que dos olhos; olhos ovalados, fuscos; sutura coronal atingindo a base do clípeo; margem superior do vértice sinuosa. Pronoto castanho-claro, com pontuação heterogênea; superfície dos lóbulos pós-oculares rugosa; metopídio arredondado; distância entre os ângulos umerais igual à largura entre os ápices dos processos supra-umerais; processos supra-umerais reduzidos, de comprimento menor que a largura da cabeça, com o ápice arredondado; elevação dorsal regularmente arredondada; ápice do processo posterior ultrapassando os ângulos internos das tégminas; área pré-apical amarelo-pálida; uma mancha negra de cada lado logo após o escutelo, junto às margens. Escutelo visível lateralmente. Tégminas com a parte basal coriácea, castanho-clara, pontuada com castanho-escuro, com uma mancha enegrecida junto à margem costal próximo à base. Asas hialinas, com venação escura. Pernas castanhas, tíbias e tarsos castanho-escuros. Abdômen castanho-claro. Genitália: edeago achatado e afilado para o ápice, coberto com microdentículos; falobase cilíndrica; parâmeros achatados largos, com ápice em gancho retorcido.

Fêmea. Desconhecida.

Material examinado. Holótipo macho de "Encruzilhada - Bahia -Brasil Motel da Divisa, XI - 1974, Alvarenga \& Seabra leg.". Parátipo: 1 macho com os mesmos dados do holótipo.

Etimologia. O nome da espécie é em homenagem à Profa Dra Danúncia Urban, Departamento de Zoologia, Universidade Federal do Paraná.

Comentário. Está espécie difere das outras por apresentar o pronoto pouco elevado, com o contorno superior regularmente arqueado, sem formar um processo dorsal distinto. Os lóbulos supra-antenais são dobrados para trás.

\section{Paracentronodus viridistriga (Walker, 1858) comb. $\mathrm{n}$.}

Fig. 33

Hemiptycha viridistriga Walker, 1858: 145; Broomfield, 1971: 385 (desig. lectótipo).

Hypheus viridistrigata [sic]; Funkhouser 1927: 142.

Hypheodana viridistriga; Metcalf \& Wade, 1965: 619.

WALKER (1858) fornece a seguinte descrição: "Castanho-escuro, avermeIhado ventralmente. Cabeça curta, larga. Pronoto grosseiramente pontuado, não alto, convexo e muito fracamente carenado na frente; parte posterior carenada, comprimida, preta ao longo da carena, formando logo após os úmeros um corno ereto, comprimido e arredondado, depois do qual uma estria esverdeada. Asas anteriores acastanhadas, pontuadas para a base. Asas posteriores acinzentadas. Comprimento do corpo 4 linhas; das asas 8 linhas. $a$, $b$. Tijuca, Rio de Janeiro".

Comentários. Os dois exemplares (fêmeas) estudados por WALKER (1858) estão depositados no The Natural History Museum (BMNH), Londres. A espécie, inicialmente, foi descrita em Hemiptycha Germar, 1833, sendo depois transferida para Hypheus Stål, 1867 e mais tarde para Hypheodana Metcalf, 1952 (FUnKHOUSER 1927; MetCalf 1952), ambos os autores considerando-a como Darninae. BROOMFIELD (1971) designou um dos síntipos como lectótipo. O material-tipo não foi examinado, porém o exame de um diapositivo do lectótipo foi suficiente para reconhecer a espécie e enquadrá-la em Paracentronodus, Centronodinae. Pela

Revta bras. Zool. 18 (Supl. 1): 255 - 267, 2001 
forma do pronoto, aproxima-se de $P$. truncatus, entretanto a elevação dorsal é menos desenvolvida e arredondada e o ápice do processo posterior não chega ao final do clavo.

\section{REFERÊNCIAS BIBLIOGRÁFICAS}

BRoOMFIELD, P.S. 1971. A catalogue of the membracid types (Homoptera; Membracidae) in the British Museum (Natural History). Bull. British Mus. (N.H.) Entomol. 25 (8): 325-386.

DEITZ, L.L. 1975. Classification of the higher categories of the New World treehoppers (Homoptera:Membracidae). North Carolina Agricult. Experim. Station. Technical Bull. 225: 1-177.

DeITZ, L.L. \& C.H. DieTRiCh 1993. Superfamily Membracoidea (Homoptera: Auchenorrhyncha). I. Introduction and revised classification with new family-group taxa. Syst. Entomol. 18: 287-296.

FUnkhousER, W.D. 1927. Membracidae. General Catalogue of the Hemiptera. Fase. 1. Massachussets, Smith College, 581p.

MetCalf, Z.P. 1952. New names in the Homoptera. Jour. Wash. Acad. Sci. 42: 226-231.

Metcalf, Z.P. \& V. Wade. 1965. General Catalogue of the Homoptera. Membracoidea. Sec. I. Raleigh, North Carolina State Univ., p. 1-743.

SAKAKIBARA, A.M. 1971. Um gênero e duas espécies novas de Centrotinae (Homoptera, Membracidae). Rev. Brasil. Biol. 31 (4): 467-470.

WALKER, F. 1858. List of the specimens of homopterous insects in the Collection of the British Museum. London, Supplement, 369p.

Recebido em 15.XII.2000; aceito em 27.VI.2001. 